\title{
PENGARUH IMPLEMENTASI WAREHOUSE MANAGEMENT SYSTEM TERHADAP INVENTORY CONTROL FINISH GOOD BERBASIS BARCODE PT. DHARANA INTI BOGA
}

\author{
${ }^{1)}$ Andi Haslindah, ${ }^{2)}$ Muh. Fadhli, ${ }^{3)}$ Adrianto, dan ${ }^{4)}$ Rahmat Mansyur \\ ${ }^{1,2)}$ Dosen Program Studi Teknik Industri Fakultas Teknik Universitas Islam Makassar \\ ${ }^{3,4)}$ Mahasiswa Program Studi Teknik Industri Universitas Islam Makassar \\ Jl. PerintisKemerdekaan KM 9 No 29 Kampus UIM, Telp 0411-588-167 \\ Email : ${ }^{1)}$ andihaslindah.dty@uim-makassar.ac.id, ${ }^{2)}$ muhammadfadhli.dty.@uim-makassar.ac.id \\ ${ }^{3)}$ adrianto@yahoo.com, ${ }^{4)}$ rahmatmansyur@yahoo.com
}

\begin{abstract}
ABSTRAK
Warehouse Management adalah sebuah management yang bertugas untuk mengorganisir masalah pergudangan. Pengorganisiran akan berjalan dengan baik apabila ditunjang dengan sistem yang tepat dan efisien. Sebuah sistem pengelolaan gudang, atau warehouse management system, adalah bagian kunci dari rantai pasokan dan terutama bertujuan untuk mengontrol pergerakan dan penyimpanan bahan dalam gudang dan proses transaksi yang terkait, termasuk pengiriman, penerimaan, penyimpanan dan pengambilan barang. warehouse management system akan mengoptimalkan tenaga kerja, mengurangi waktu proses, mengurangi proses inventory yang tidak perlu yang pada akhirnya akan meningkatkan pelayanan kepada customer. Tidak setiap gudang dapat atau harus menerapkan warehouse management system karena adakalanya suatu gudang cukup menerapkan system pergudangan yang sederhana saja, misalnya untuk gudang dengan skala kecil. Oleh karena itu, penggunaan warehouse management system perlu dioptimalkan agar tidak merugikan pihak warehouse.
\end{abstract}

Kata Kunci: warehouse management system, barkode.

\section{PENDAHULUAN}

Perkembangan perusahaan di Indonesia makin pesat baik perusahaan yang bergerak dibidang produksi maupun perusahaan yang bergerak dibidang jasa. Semakin meningkatnya persaingan di dunia usaha membuat semakin meningkatnya kinerja setiap aktifitas di setiap perusahaan, seluruh perusahaan berlomba memberikan pelayanan yang terbaik bagi konsumen. Setiap perusahaan memerlukan gudang sebagai tempat penyimpanan barang/persediaan, baik persediaan barang jadi, barang setengah jadi, maupun barang jadi. Dalam kondisi ini perusahaan tentunya tidak terlepas dengan service dan manage gudang profesional dan proporsional.

Gudang merupakan suatu hal yang penting tentunya karena gudang merupakan tempat penyimpanan segala jenis barang yang diperlukan bagi sebuah perusahaan, jadi bisa di analogikan bahwa gudang adalah pusat dimana semua barang dikumpulkan dan titik awal dimana barang akan disalurkan ke retailer ataupun lansung ke konsumen. Berdasarkan hal tersebut tercermin bahwa aktifitas didalam gudang sangatlah rumit karena memang fungsi dan manfaat sangatlah penting bagi perusahaan. Gudang tidak hanya sebagai tempat penyimpanan barang sementara, untuk ini diperlukan suatu alat untuk mengatur semua ini. Dalam hal ini adalah sistem atau aplikasi. Secara ringkas sistem manajemen gudang mengandung pemahaman yaitu pengelolaan dari aktifitas yang saling terkait dalam aktifitas penyimpanan barang sementara.

Salah satu aplikasi yang digunakan dalam pengaturan aktifitas gudang adalah WMS (Warehouse Management System) yang merupakan kunci utama dalam supply chain, dimana yang menjadi tujuan utama adalah 
mengontrol segala proses yang terjadi di dalamnya seperti shipping (pengiriman), receiving (penerimaan), putaway (penyimpanan), move (pergerakan), dan picking (pengambilan). WMS yang berdasarkan prosedur komputerisasi digunakan sebagai alat dalam membantu pengendalian persediaan barang barang di gudang.

\section{METODOLOGI PENELITIAN}

Metode penelitian yang dilakukan adalah metode penelitian kualitatif deskripsi Dalam penelitian ini menggunakan teknik analisis model Miles and Huberman. Aktivitas analisis data yaitu data reduction, data display, dan conclusion drawing/verification. Metode yang digunakan untuk mengumpulkan data dalam penelitian ini adalah studi pustaka dan observasi.

\section{ANALISA DAN PEMBAHASAN}

Efektivitas sistem penyimpanan barang bergantung pada beberapa karakteristik internal dan eksternal. Karakteristik internal meliputi kapasitas penyimpanan, kemudahan akses ke lokasi penyimpanan, kompleksitas struktur internal dan tingkat teknologi informasi. Sedangkan karateristik eksternal seperti jenis produk, jumlah produk, jumlah persediaan untuk disimpan, dan tipe aliran barang masuk dan keluar.

Pada laporan space utility gudang finish good, menunjukkan kapasitas gudang dalam menampung produk yang dimuat dalam satuan pallet. Kapasitas gudang menunjukkan jumlah produk yang ditampung di dalam gudang, baik yang berada di gudang finish good maupun yang berada pada area produksi. Jumlah total produk tersebut akan dibagi jumlah karton yang dapat ditampung satu pallet. Jumlah pallet yang terpakai tersebut kemudian menjadi kapasitas daya tampung gudang finish good. Kapasitas gudang finish good mengalami kelebihan kapasitas pada saat belum diberlakukannya WMS. Jenis produk diletakkan acak pada racking yang kosong tanpa memperhatikan klasifikasi penempatan produk fast moving maupun produk slow moving.
Tabel dibawah menunjukkan kapasitas gudang sebelum penerapan WMS dimana persentase space utility menunjukkan angka $380 \%$. Angka ini diperoleh dari jumlah total dus produk dalam gudang yaitu sebanyak 3.107 dus dibagi dengan kapasitas gudang normal yaitu sebanyak 818 dus, diperolehlah persentase $380 \%$. Hal ini berarti bahwa penempatan produk sudah melebihi jauh dari kapasitas normalnya.

Tabel 1. Space Utility sebelum WMS

\begin{tabular}{|l|r|r|r|r|r|}
\hline \multirow{2}{*}{ Produk } & \multicolumn{2}{|c|}{ GFG PT K } & \multicolumn{2}{c|}{ PRODUKSI } & \multirow{2}{*}{ TOTAL GFG } \\
\cline { 2 - 5 } & \multicolumn{1}{|c|}{ Dus } & \multicolumn{1}{c|}{ Palet } & Dus & Palet & \\
\hline MTB & 262.848 & 1.555 & - & - & 262.848 \\
\hline MTG & 110.057 & 651 & - & - & 110.057 \\
\hline MTA & 29.535 & 175 & - & - & 29.535 \\
\hline MTC & - & - & - & - & - \\
\hline MTM & 17.410 & 134 & - & - & 17.410 \\
\hline JBC-04 & - & - & - & - & - \\
\hline JBC-04 170 & 75.541 & 447 & - & - & 75.541 \\
\hline JDO-07 & 24.514 & 145 & - & - & 24.514 \\
\hline JDO-01 & & - & - & - & - \\
\hline \multicolumn{1}{|c|}{ JDB-1 220 } & & - & - & - & - \\
\hline TOTAL & $\mathbf{5 1 9 . 9 0 5}$ & 3.107 & - & - & 519.905 \\
\hline KAPASITAS & 138.242 & $\mathbf{8 1 8}$ & & & 138.242 \\
\hline SPACE UTILITY & $\mathbf{3 7 6 \%}$ & $380 \%$ & & & $376 \%$ \\
\hline GAP & 381.663 & 2.289 & - & - & 381.663 \\
\hline
\end{tabular}

Pada tabel di bawah menunjukkan laporan space utility setelah penerapan WMS. Tabel ini memperlihatkan bahwa jumlah produk pada gudang finish good berada pada persentase $40 \%$. Hal ini berarti bahwa produk jumlah produk yang berada pada gudang tidak melebihi kapasitas gudang tersebut dan penempatan produk disesuaikan dengan klasifikasi dan daya tampung gudang finis good.

Tabel 2. Space Utility setelah WMS LAPORAN SPEACE UTILITY SEPTEMBER 2017

\begin{tabular}{|c|c|c|c|c|c|}
\hline \multirow{2}{*}{ Produk } & \multicolumn{2}{|c|}{ GFG PT K } & \multicolumn{2}{|c|}{ PRODUKSI } & \multirow{2}{*}{ TOTAL GFG } \\
\hline & Dus & Palet & Dus & Palet & \\
\hline MTA-1 180 & 2.892 & 17 & - & - & 2.892 \\
\hline MTB-1 1 180 & 20.739 & 123 & - & - & 20.739 \\
\hline MTG-1 180 & 1.392 & 8 & - & - & 1.392 \\
\hline MTE-1 180 & - & - & - & $=$ & - \\
\hline FDO-1 200 & 109 & 1 & - & - & 109 \\
\hline FDO-2 200 & 2.693 & 21 & - & $=$ & 2.693 \\
\hline JBC-4 150 & 13.270 & 79 & - & - & 13.270 \\
\hline JBC-9 150 & 572 & 3 & - & $=$ & 572 \\
\hline JDO-7 150 & 5.093 & 30 & - & - & 5.093 \\
\hline JDE-1 220 & 4.697 & 36 & - & - & 4.697 \\
\hline JDB-7 220 & 1.122 & 9 & - & - & 1.122 \\
\hline OाT450 & 691 & 14 & - & - & 691 \\
\hline TOTAL & 53.270 & 326 & - & - & 53.270 \\
\hline KAPASITAS & 138.242 & 818 & & 0 & 138242 \\
\hline SPACE UTILITY & $39 \%$ & $40 \%$ & $0 \%$ & $0 \%$ & $39 \%$ \\
\hline GAP & (84.972) & (492) & - & - & $(84,972)$ \\
\hline
\end{tabular}

Efektivitas putway ditandai dengan lebih singkatnya proses putway pada penempatan produk yang telah ditunjukkan TO. Pada TO 
dengan jelas tertera racking, storage type, dan storage bin tujuan produk Produk harus ditempatkan pada storage bin yang tertera pada lembar TO. Operator forklift harus dengan tepat menempatkan produk.

Proses pengambilan produk sebelum penerapan WMS adalah dengan hanya menggunakan form checker. Adapun pengambilan produk yang berdasarkan ED hanya mengacu pada koordinasi lisan antar shift mengenai letak produk yang EDnya lebih cepat. Kondisi seperti ini bisa menimbulkan kesalahpahaman jika hanya koordinasi lisan.

Untuk menjaga akurasi persediaan di gudang barang jadi, secara rutin dilakukan perhitungan fisik terhadap produk yang ada di gudang. Perhitungan ini dilakukan setiap hari dan juga rutin sekali sebulan. Perhitungan persediaan ini membandingkan data persediaan yang tercatat dalam sistem SAP dengan fisik produk yang terdapat digudang. Perhitungan ini membandingkan antara item produk, jumlah per palet, penempatan produk pada storage bin, dan batch tiap-tiap produk. Perhitungan ini dilakukan oleh inputter, verifikator, dan kepala gudang yang mana pihak verifikatorbukan berasal dari staf gudang.

Tabel 3. Data Stock opname bulanan tahun 2017

\begin{tabular}{|c|c|c|c|c|c|c|c|c|c|c|c|c|c|c|c|c|c|c|c|c|c|c|c|}
\hline & \multicolumn{3}{|c|}{ bai } & \multicolumn{3}{|c|}{ Fisuia } & \multicolumn{2}{|c|}{$\mathrm{K}_{\mathrm{tz}}$} & \multicolumn{3}{|c|}{$k i$} & \multicolumn{3}{|c|}{116} & \multicolumn{2}{|c|}{ iti } & \multicolumn{3}{|c|}{ di } & \multicolumn{2}{|c|}{ logos } & \multicolumn{2}{|c|}{ Sefente } \\
\hline & $\underline{g P}$ & \begin{tabular}{|l|l|}
$\mathrm{Fat}$ \\
\end{tabular} & $\$$ & $\mathscr{P P}$ & 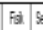 & *at s & $\begin{array}{lll}H P & F\end{array}$ & 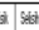 & 6 & $\mathrm{Fol}$ & swat & $\$$ & 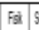 & wat 9 & \begin{tabular}{|l|l}
$* F F$ \\
\end{tabular} & 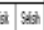 & $\%$ & $\mathrm{Fad}$ & sकt & $9: F$ & 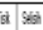 & $\%$ & $\mathrm{Fai} 9 \mathrm{se}$ \\
\hline 700 & & & & & & & & & 49 & 490 & & 5 & 5 & & 486 & 45 & 178 & 诚 & & & ix & 5 & (2) \\
\hline FOQ & & & & & & & & & & & & 128 & 43 & & & & & ๒1 & & & 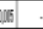 & 50 & 60 \\
\hline 80 & 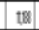 & $t \pi$ & & $\mid 76$ & 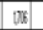 & & 101 & & 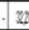 & 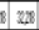 & & 390 & 289 & & 6089 & & & $x=0$ & & $\pi$ & (19) & 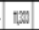 & 단 \\
\hline 89 & & & & & & & 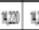 & & $7 x$ & 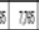 & & (5) & 40 & & 58 & & यक & या & & & (1) & 组 & เ日8 \\
\hline (18) & & & & & & & & & 2 & 606 & & 6 & 6 & & $x=18$ & & 80 & $8 \%$ & & & 4 & $5 \pi$ & $5 \pi$ \\
\hline (18) & & & & & & & & & & & & & & & & & . & 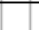 & & 7 & & (5) & (15) \\
\hline 200 & 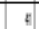 & $\begin{array}{ll}t \\
\end{array}$ & & tin & $4 \pi$ & & $\mathrm{ve} 1$ & 68 & in & \begin{tabular}{|l|l|}
58 \\
\end{tabular} & & 20 & 280 & & 628 & & $x$ & 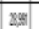 & & & 897 & 语 & 语 \\
\hline VIN & (9: & \begin{tabular}{|l|}
597 \\
\end{tabular} & & 480 & 4XI & & 58 & ta & in & 50 & & v2 & (2n & & 484 & & & 5 & & & w & & 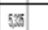 \\
\hline V18 & (20) & 60 & & $95 x$ & 95 & & 11 & & 35 & 7897 & & 45 & 65 & & 1910 है। & & & eogs & & 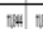 & 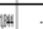 & 997 & 99 \\
\hline $\mathrm{VIra}$ & 898 & 890 & & 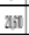 & 251 & & $5 \mathrm{~F}$ & $y$ & 2 & $3 x$ & & USE & ue & & is 1 & & 7 s: & is & & 80 & 8 & & \$ \\
\hline $\mathrm{NOE}$ & & & & & & & $\$ \infty$ & $x$ & & $\mathbb{1 0}$ & & & & & 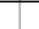 & & & 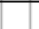 & & & & & \\
\hline Bant? & $y 5$ & 啊 & & 76 & "45 & & ข้า ก & & sर & 8918 & & 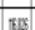 & 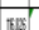 & & & & mp & $\mathrm{mm}$ & & & 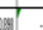 & & 89 \\
\hline
\end{tabular}

Pada tabel di atas terlihat bahwa perhitungan fisik dan SAP selama tahun 2017 tidak pernah mengalami selisih. Penempatan barang di gudang sudah dilakukan secara otomatis begitu pula dengan pengambilan barang pada saat pengiriman juga mengacu pada TO yang ditunjuk oleh sistem secara otomatis pula berdasarkan batch terlama (FIFO).

\section{PENUTUP}

\section{Kesimpulan}

PT. Dharana Inti Boga telah menerapkan Sistem Manajemen Pergudanga atau Warehouse Management System (WMS) untuk mengontrol segala proses yang terjadi di dalamnya seperti shipping (pengiriman), receiving (penerimaan), putaway (penyimpanan), move (pergerakan) dan picking (pengambilan). Tujuan dari WMS adalah untuk menyediakan satu set prosedur komputerisasi untuk menangani penerimaan dan pengiriman barang, mengelola fasilitas penyimpanan (misalnya racking, dll), mengelola stock barang untuk picking, packing dan shiping.

\section{DAFTAR PUSTAKA}

Ahmad Hanafie, Andi Haslindah, Saripuddin M (2017), Karakteristik Antropometri Pengguna Mesin Perontok Padi (Combine Harverter) Pengelolaan Hasil Panen yang Ergonomis, Prosiding Seminar Nasional Telnologi Indonesia V, hal 52-57, Makassar 12 Juli 2017.

Ahmad Hanafie (2007), Modifikasi Helm Standar Kendaraan Roda Dua Yang Ergonomis Bagi Penguna Telpon Seluler, Jurnal Iltek, Vol. II, Nomor 4, April 2007, Hal 313-319, Fakultas Teknik Univ. Islam Makassar.

Ahmad Hanafie, A.Haslindah, Muh. Fadhli (2015), Pengembangan Mesin Perontok Padi (Combine Harverter) yang Ergonomis Untuk Meningkatkan Produksi, Prosiding Seminar Nasional Tahunan Teknik Mesin Indonesia-XIV, Banjarmasing, 7-8 Oktober 2015.

Ahmad Hanafie, Hammada Abbas, Lawalenna, Sumarni Hami (2016), Study Of Vehicles Utilities And LoadUnloading Facilities Of City Public Transport Based On Ergonomics Assessment, International Journal of Advances in Scientific Research and Engineering (ijasre.net) Volume-1, Issue3, December - 2016.

Agus, Ristono. 2008. Menajemen Persediaan. Yogyakarta: Graha Ilmu. 
Baroto, T. 2002. Perencanaan Dan Pengendalian Produksi. Jakarta: Ghalia Indonesia.

Fogarty, Donald W., Blackstone, John H. Jr., and Hoffman, T. R. 1991. Production and Inventory Management. Cincinnati: Colledge Division South-Western Publishing Co.

Gaspersz, Vincent. 1998. Production Planning And Inventory Control Berdasarkan Pendekatan Sistem Terintegrasi MRP II dan JIT Menuju Manufacturing 21. Jakarta: Gramedia Pustaka Utama.

Hadiguna, R. A., dan Setiawan, H. 2008. Tata Letak Pabri . Yogyakarta.

Oden, Howard W., Langenwalter, Gary A., and Lucier, Raymond A. 1993. Handbook of Material \& Capacity Requirements Planning. United State of America: McGraw Hill.

Sugiyono. 2010. Memahami Penelitian Kualitatif. Bandung: Alfabeta.

Suradi, H. Abbas, W. Tjaronge, V. Sampebulu, Estimation of Standard Time in Production of Light Weight Brick Manufacturing Using Ball Mill, International Journal of Advances in Scientific Research and Engineering (ijasre.net), ISSN 2454-8006 Volume-2, Issue-1,January-2016

Suradi, H. Abbas, W. Tjaronge, V. Sampebulu Analysis Standard Time Section 1 of Brick Light Production (Autoclave Aerated Concrete/AAC), International Journal Of Current Research, (www.journalcra.com) ISSN0975-833X, Volume 8, Issue 01, PP.25307-25310, January,2016

Suradi, H. Abbas, W. Tjaronge, V. Sampebulu Model Optimization Labour Based Workload on The Production Process of AAC (Case Study PT.BSB Kalla Block), International Journal of Current Research, (www.journalcra.com) ISSN-0975-833X, Volume 8, Issue 05, PP.30440-30444, May, 2016
Suradi, H. Abbas, W. Tjaronge, V. Sampebulu, Measurement Workload on The AAC Production Process in PT. BSB Kalla Block, International Conference on Society Of Engineering \& Technology, Computer, Basic \& Applied Sciences (ECBA), ISBN : 978-969-670-448-1, May 28-29, 2016, Jakarta, Indonesia, Academic Fora, www.academicfora.com, Office Address : M2-17-01 Tower 2, Lvel 17 Atrium, Bandar Sri Damansara, 52200 Kuala Lumpur, Malaysia.

Yunarto, Holy Icun. 2006. Business Concept Implumentation Series. Jakarta: PT. Elex Media Komputindo. 